\title{
LACCASE CONCENTRATION BY FOAM FRACTIONATION OF CERRENA UNICOLOR AND PLEUROTUS SAPIDUS CULTURE SUPERNATANTS
}

\author{
Michał Blatkiewicz ${ }^{* 1}$, Anna Antecka ${ }^{1}$, Andrzej Górak ${ }^{1,2}$, Stanisław Ledakowicz ${ }^{1}$ \\ ${ }^{1}$ Lodz University of Technology, Faculty of Process and Environmental Engineering, ul. \\ Wólczańska 213, 90-942, Łódź, Poland \\ ${ }^{2}$ Dortmund University of Technology, The Department of Biochemical and Chemical Engineering, \\ Emil-Figge-Straße 70, D-44227 Dortmund, Germany
}

\begin{abstract}
Foam fractionation process for concentration of laccases from two Basidiomycete strains under different process conditions was investigated. Culture supernatants of Cerrena unicolor and Pleurotus sapidus containing active laccase were used with and without surfactant additives. Two surfactants: cationic cetrimonium bromide (CTAB) and non-ionic Polysorbate 80 were applied in the range from $0.2 \mathrm{mM}$ to $1.5 \mathrm{mM}$. The $\mathrm{pH}$ levels ranging from 3 to 10 were examined with particular attention to $\mathrm{pH}=4$, which is close to the $\mathrm{pI}$ of the enzymes. Results show that the source of the enzyme is significant in terms of partitioning efficiency in a foam fractionation process. Laccase from Cerrena unicolor showed the best activity partitioning coefficients between foamate and retentate of almost 200 with yields reaching $50 \%$ for $\mathrm{pH} 7.5$ and concentration of CTAB $c_{\mathrm{CTAB}}=0.5 \mathrm{mM}$, whereas laccase from Pleurotus sapidus showed partitioning coefficients of up to 8 with $25 \%$ yield for $\mathrm{pH} 4$ and $c_{\mathrm{CTAB}}=0.5 \mathrm{mM}$.
\end{abstract}

Keywords: foam fractionation, Laccase, CTAB, Polysorbate 80

\section{INTRODUCTION}

Laccases (EC 1.10.3.2, p-diphenolic oxidases) are enzymes which belong to the group of oxidoreductases. They can be produced by various organisms, such as plants, insects, bacteria (Claus and Filip, 1997; Diamantidis et al., 2000; Harvey and Walker, 1999), but are most commonly found as extracellular products of fungi, especially the ones causing white rotting of wood (Songulashvili et al., 2007). Their purpose in nature is to decompose long lignocellulosic chains into molecules of lower mass, and therefore provide the host with a carbon source (Cohen et al., 2002; Reddy et al., 2003). However, they are also able of decomposing a variety of aromatic compounds, like aromatic amines, substituted phenols, or thiols (Xu, 1996).

Although biotechnology is currently one of the most advancing branches of science, downstream processing of biological products remains a time-consuming and expensive task (Raja et al, 2011). Therefore, a lot of research is focused on finding and developing novel, cost-effective, efficient methods of bioproduct separation and recovery with satisfying selectivity towards the desired product and granting its stability in the process. Various downstream processing methods of laccase have been investigated, including chromatographic methods (Scherer and Fischer, 1998) and aqueous two-phase extraction (Blatkiewicz et al., 2016; Prinz et al., 2014). One of the promising, currently investigated methods is foam fractionation $(\mathrm{FF})$. It is a bubble separation technique which allows for separation of 
amphiphilic molecules, such as proteins, from their aqueous solutions (Lemlich, 1968). The principle of the process is to generate liquid-gas interface in the form of foam by continuously feeding a batch of the desired bioproduct's aqueous solution with dispersed inert gas in a column. The emergent foam, enriched in the product, is then collapsed with the use of lowered pressure and collected as a foamate at the column outlet (Burghoff, 2012). As the bubbles migrate upwards, which is caused by the foam buildup within the column, their water content gets lower due to gravitational and capillary forces. This causes draining of the foam and coalescence of the constituent bubbles, and thus, further concentration of the product within the foam (Du et al., 2000; Merz et al., 2011a).

Foam fractionation has a number of advantages that makes it a feasible process. Not only is it carried out in mild conditions for biological molecules, but also it is suitable for diluted solutions (Uraizee and Narsimhan, 1990). Moreover, it is cost-effective and environment-friendly since it is not necessary to use chemical additives other than insignificant amounts of surfactant, while only inert gas is involved (Stowers et al., 2009). Additionally, since it is mostly amphiphilic compounds that concentrate on the liquid-gas interface, foam fractionation tends to be selective towards proteins.

Foam fractionation is used mostly as an early step in bioproduct recovery (Merz et al, 2011b). Therefore it is often applied to crude supernatants, in which the protein content is very low. This may cause high surface tensions and decrease the liquid's ability to foam. This is why surfactant supplementation is utilized for such processes to lower surface tensions and stabilize the structure of bubbles (Linke et al., 2007).

Although laccases produced by different hosts serve the same function, their structural differences often lead to different behaviors in downstream processes (Linke et al., 2007; Prinz et al., 2012). Foam fractionation of laccase has been reported in literature (Gerken et al., 2006; Linke et al., 2007), but the published research involved only commercially available pure laccase from Trametes spec., not from crude supernatants of fungal cultures. The purpose of this paper was to study differences in efficiency of foam fractionation of laccase-containing supernatants produced separately by two Basidiomycete strains: Cerrena unicolor and Pleurotus sapidus with the use of two surfactants: cationic cetyltrimethylammonium bromide (CTAB) and non-ionic polyoxyethylene (20) sorbitan monooleate (Polysorbate 80 ) under different $\mathrm{pH}$ values.

\section{MATERIALS AND METHODS}

The $C$. unicolor strain was initially grown on agar plates containing malt extract and mycological peptone. The $P$. sapidus strain was grown on agar plates containing malt extract and soybean peptone After 7 days of growth the mycelium was homogenized with water with the use of IKA T25 Basic homogenizer at $8000 \mathrm{rpm}$ and transferred into $200 \mathrm{ml}$ flasks, containing Lindeberg-Holm growth medium for C. unicolor (Lindeberg and Holm, 1952) and standard culture medium suggested by Zorn for P. sapidus (Zorn et al., 2003). The medium was supplemented with $\mathrm{Cu}^{2+}$ source, without the use of inductors. The liquid fermentation was conducted in a Certomat BS-1 shaker at $110 \mathrm{rpm}$. The temperature of $28^{\circ} \mathrm{C}$ for C. unicolor and $26^{\circ} \mathrm{C}$ for P. sapidus was applied. The fermentation lasted 10 or 12 days respectively. Then, the supernatants were filtrated and frozen in $100 \mathrm{ml}$ containers at $-20{ }^{\circ} \mathrm{C}$. The defrosted supernatants showed initial activities of about $1500 \mathrm{U} / 1$ and $700 \mathrm{U} / 1$ respectively in relation to ABTS at $\mathrm{pH}=4.5$ in $25^{\circ} \mathrm{C}$.

Cetyltrimethylammonium bromide (CTAB) was purchased from Sigma-Aldrich. Polysorbate 80 was purchased from Fluka. 2,2'azino-bis-(3-ethylobenzothiazoline-6-sulphonic acid) (ABTS) with the purity of $98 \%$ was purchased from Sigma-Aldrich.

The activity of laccase was measured using the ABTS assay according to Majcherczyk et al. (1998). The activity was defined as the amount of the enzyme catalyzing one $\mu \mathrm{mol}$ of ABTS per minute. It was 
determined by the oxidation rate of ABTS molecules over time. The pH was adjusted to 4.5 using McIlvaine buffer. All the measurements were performed using a T80+ UV/Vis Spectrometer from PG Instruments Ltd. The measurements of absorbance increment were performed in $25^{\circ} \mathrm{C}$ at $420 \mathrm{~nm}$ wavelength over $0.5 \mathrm{~min}$. The extinction coefficient for ABTS at $420 \mathrm{~nm}$ wavelength is equal to $\varepsilon=0.04321 \mathrm{l} /(\mathrm{mmol} \mathrm{cm})$. If the sample's activity was too high for the spectrometer's range, it was diluted accordingly. To calculate the enzymatic activity, the following equation was used:

$$
a c t\left[\frac{U}{l}\right]=\frac{\Delta E \cdot D \cdot V_{t}}{\Delta t \cdot V_{s} \cdot d \cdot \varepsilon}
$$

The experimental setup has been presented in Fig. 1. It consisted of a glass column of $62 \mathrm{~cm}$ in length and inner diameter of $3 \mathrm{~cm}$, a foam collector, a Büchner flask connected to a pump producing low under-pressure, and a compressed air distributor equipped with a reducing valve set to 2 bar and an electronic valve for flux control. The column was equipped with a porous glass disperser at the bottom. Compressed air flowed to the disperser through an electronic valve which set the airflow to $2.4 \mathrm{l} / \mathrm{h}$.

After fixing the airflow, $100 \mathrm{ml}$ of the culture supernatant supplemented with surfactant was poured into the column and the foaming started. Then, a foam collector was installed at the top of the column which directed the foam into a Büchner flask equipped with a funnel to break down the foam. Each experiment was conducted until the foam was no longer able to reach the top of the column before collapsing. Then the experiment was terminated and volumes of the foamate (the collapsed foam) and the retentate (the liquid remaining in the column after the process) were measured. Samples of each phase were taken, and their enzymatic activities were measured. Every experiment was performed at room temperature.

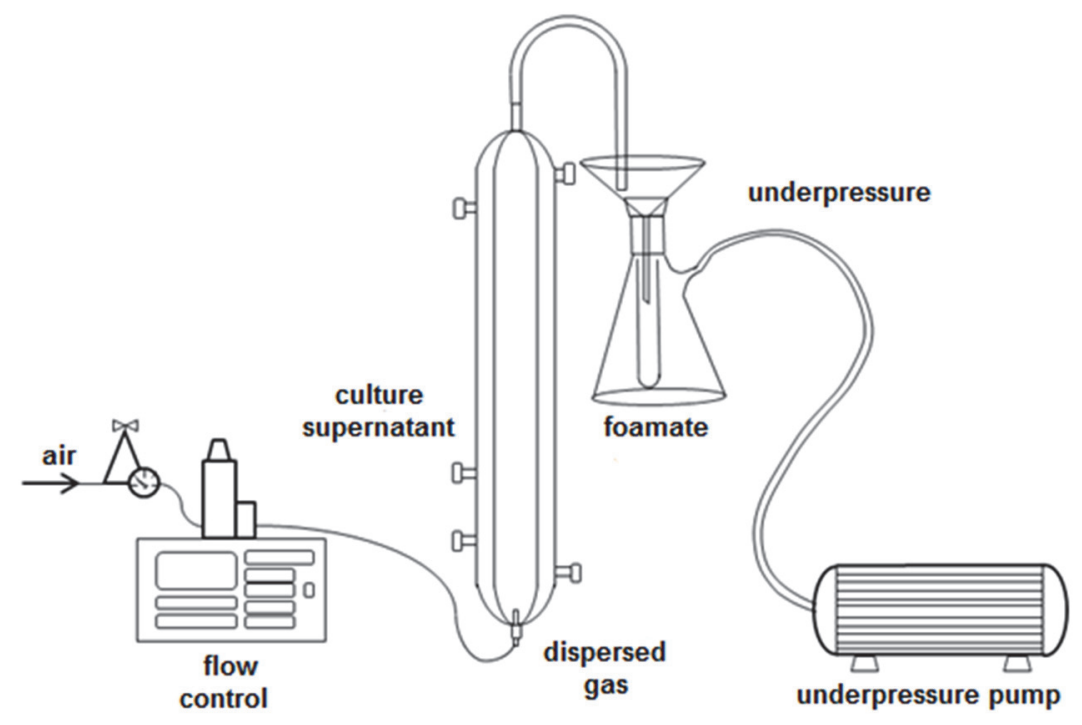

Fig. 1. Foam fractionation equipment setup

There are two major parameters which determine the efficiency of foam fractionation: the yield (recovery) in the foamate $(Y)$, which informs about the recovery of the enzyme in a given phase and the activity partitioning coefficient $\left(k_{a c t}\right)$, which informs about the ratio of enzymatic activities between the phases.

$$
\begin{gathered}
Y=\frac{V_{\text {foam }} \cdot a c t_{\text {foam }}}{V_{\text {ini }} \cdot a c t_{\text {ini }}} \\
k_{\text {act }}=\frac{a c t_{\text {foam }}}{a c t_{\text {ret }}}
\end{gathered}
$$




\section{RESULTS AND DISCUSSION}

Preliminary experiments showed that the foaming properties of pure culture supernatants of both Cerrena unicolor and Pleurotus sapidus are not enough for the foam to reach the top of the column without breaking, so surfactant additives had to be used. Cetyltrimethylammonium bromide (CTAB) is a recommended surfactant for foam fractionation of laccase. However it may lower its recovery due to formation of stable complexes which deactivate laccase molecules (Linke et al., 2007; Walker and McCallion, 1980).

As stated by Shea et al. (2009), proteins are most hydrophobic at their isoelectric points $(p I)$, which should lead to optimal conditions for foam fractionation, although it may also lead to their precipitation and aggregation. However, there have been reports of $\mathrm{pH}$ values varying significantly for the proteins' $p I$ which proved to be more effective (Bacon et al., 1988; Chai et al., 1998; Linke et al., 2007). The isoelectric points of the laccases were determined by isoelectric focusing. The $p I$ of laccases from both C. unicolor and P. sapidus were between 3 and 5. In general, throughout the experiments, the foaming time was between 40 and 60 minutes, and volumes of collected foamates were between 2.5 and $5.0 \mathrm{ml}$.

In order to choose the optimal $\mathrm{pH}$ for the process, a set of experiments with a constant CTAB concentration and varying $\mathrm{pH}$ values was conducted. Linke et al. (2007) chose the range of $c_{\mathrm{CTAB}}=0.4-1.2 \mathrm{mM}$ for their experiments with satisfying results. Therefore for the initial experiment of $\mathrm{pH}$ screening, the surfactant concentration was chosen to be $0.5 \mathrm{mM}$, which is about half of the surfactant's critical micelle concentration $(0.9-1.0 \mathrm{mM})$. The results were presented in Figs. 2 and 3.

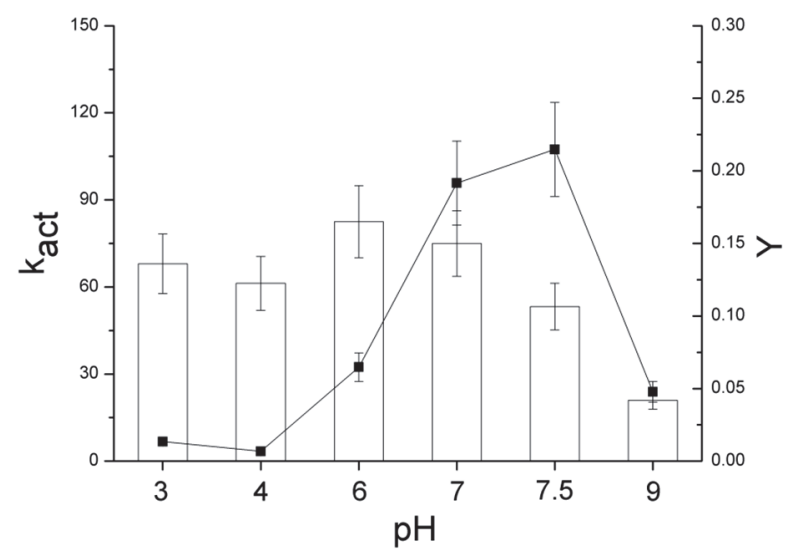

Fig. 2. Influence of $\mathrm{pH}$ on enzyme partitioning and foamate yield of laccase from C. unicolor at $c_{\mathrm{CTAB}}=0.5 \mathrm{mM}$.

(-) activity partitioning coefficient, ( $\square$ ) yield in the foamate

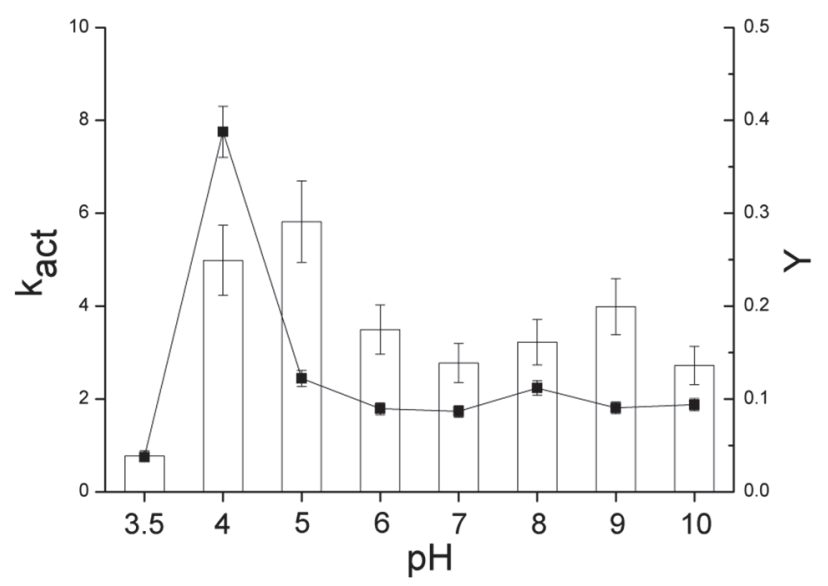

Fig. 3. Influence of $\mathrm{pH}$ on enzyme partitioning and foamate yield of laccase from P. sapidus at $\mathrm{c}_{\mathrm{CTAB}}=0.5 \mathrm{mM}$.

(匹) activity partitioning coefficient, (๑) yield in the foamate 
The $\mathrm{pH}$ had a significant influence on the effectiveness of the foam fractionating process for laccases from both hosts. As seen in Fig. 2., the highest activity partitioning coefficient (around 110) was achieved at $\mathrm{pH}=7.5$, whereas at $\mathrm{pH}=4$, which is close to the isoelectric point, the partitioning of the enzyme towards the foamate was very low. The differences in yields were less significant. In the case of $P$. sapidus laccase (Fig. 3), regardless of the $\mathrm{pH}$ value, the partitioning of laccase towards the foam was much less effective than in the case of $C$. unicolor laccase. The highest activity partitioning coefficient was no higher than 8 . However, as opposed to C. unicolor laccase, foam fractionation of laccase from $P$. sapidus showed the best results for both activity partitioning and yield, at $\mathrm{pH}$ values close to the $p I$ of the enzyme. It can be noticed that the highest yields do not line up with the highest partitioning coefficients. This is caused by the fact that at various $\mathrm{pH}$ conditions the foaming of the system can lead to carrying excess water with the foam and thus diluting the foamate. Since the volume of the foamate phase is usually very low $(2-5 \mathrm{ml})$, even slight changes in volume can significantly decrease the partitioning coefficients. Thus a trade-off situation between high yield and high partitioning coefficient may occur.

The differences in partitioning between these two types of laccases in relation to their $p I$ are very clear. While in the case of $P$. sapidus laccase, the $\mathrm{pH}$ in proximity to the molecule's $p I$ resulted in highest $k_{\text {act }}$, for $C$. unicolor laccase it was quite the opposite: setting the $\mathrm{pH}$ away from the molecule's $p I$ increased the partitioning towards the foam. Li et al. (2016) suggest that although at $\mathrm{pH}$ deviating from $p I$ the repulsion between molecules increases due to increasing zeta potentials, it also reduces thickness of the foam. The thin foam may result in a low volume of foamate, and thus higher enrichment in the phase.

Although increased concentration of surfactants increases the foamability of the system, adsorption competition may occur at the gas-liquid interface (Shea et al., 2009). Therefore, even though at higher surfactant concentrations the recovery yields are increased (Linke et al., 2007), the enrichment within the foam may decrease, as more water is transported within the foam with lower concentration of the desired protein. To study this, a second set of experiments was conducted to investigate the surfactant concentration that can be treated as a compromise between partitioning coefficient and yield. Based on prior results, two $\mathrm{pH}$ values were chosen for the investigation of the CTAB concentration on the foam fractionation effectiveness: $\mathrm{pH}=4$, which is close to the protein's $p I$, and the neutral $\mathrm{pH}=7$, which was highly effective for fractionation of the C. unicolor laccase.

As expected, the yield in the foamate maintained the consecutive increase trend as the CTAB concentration was increased, both in the case of $C$. unicolor laccase (Figs. 4, 5) and P. sapidus laccase (Figs. 6,7).

For the C. unicolor laccase at $\mathrm{pH}=4$ (Fig. 4.), even significantly increased concentrations did not cause the partitioning coefficients or recovery yields to increase satisfactorily. It can be noticed that one experimental point exceeded the surfactant's critical micelle concentration, which led to no increase in activity partitioning but with slightly higher recovery yield. However, as presented in Fig. 5, at $\mathrm{pH}=7$ the differences in foamate enrichment were significant. The process achieved its maximum partitioning coefficient at $\mathrm{CTAB}$ concentration of $0.5 \mathrm{mM}$, where $k_{\text {act }}$ value reached almost 200 . At higher CTAB concentrations the partitioning coefficient dropped significantly.

In the case of $P$. sapidus laccase, the results were analogous. At $\mathrm{pH}=4$ (Fig. 6.) there was a spike of higher foam enrichment at CTAB concentration of $0.5 \mathrm{mM}$, where the partitioning coefficient reached the value of 8 . At neutral $\mathrm{pH}$ (Fig. 7.) the activity partitioning coefficient was unaffected by the surfactant concentration increase, while the foamate yields increased, but did not exceed 0.2 at $c_{\mathrm{CTAB}}=0.7 \mathrm{mM}$. 


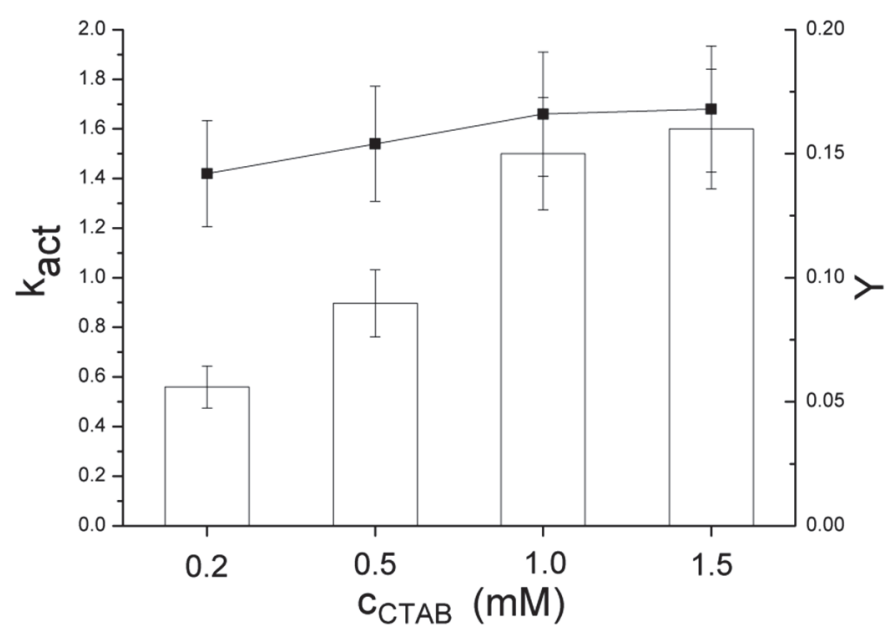

Fig. 4. Influence of CTAB concentration on enzyme partitioning and foamate yield of laccase from C. unicolor at $\mathrm{pH}=4$. ( $(\mathbf{)})$ activity partitioning coefficient, ( $\square$ ) yield in the foamate

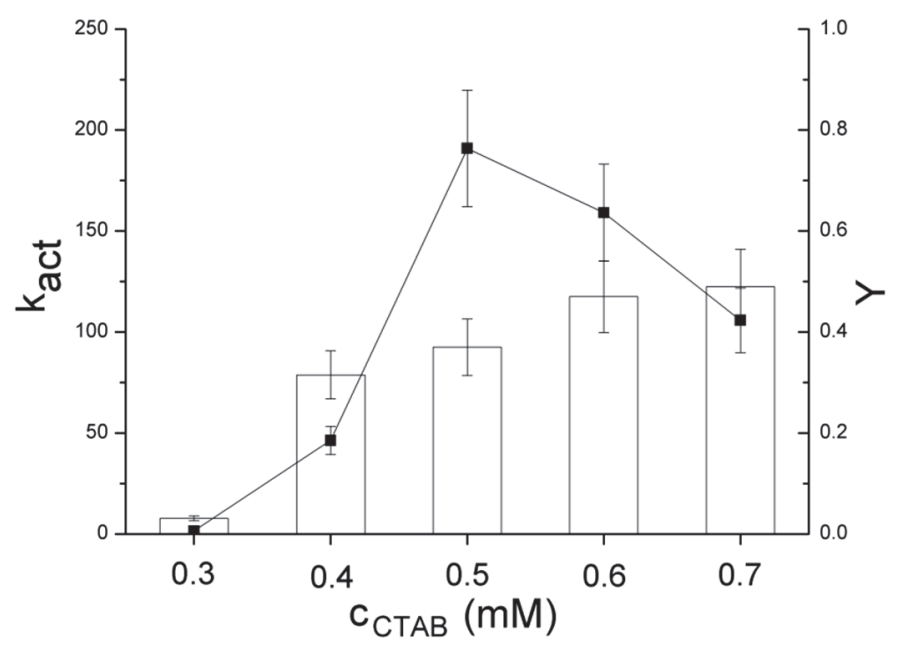

Fig. 5. Influence of CTAB concentration on enzyme partitioning and foamate yield of laccase from C. unicolor at $\mathrm{pH}=7$. ( $)$ activity partitioning coefficient, ( $\square$ ) yield in the foamate

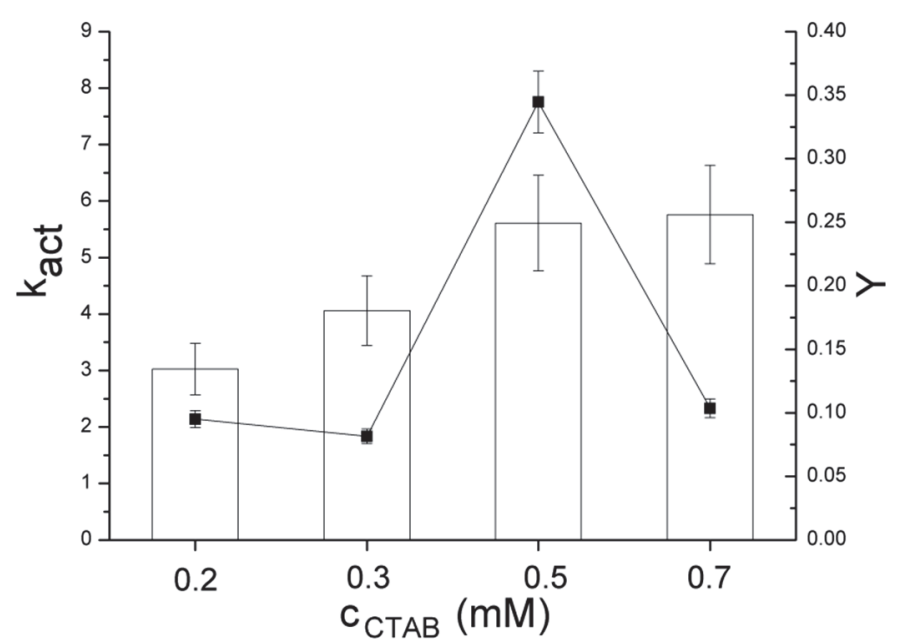

Fig. 6. Influence of $\mathrm{CTAB}$ concentration on enzyme partitioning and foamate yield of laccase from P. sapidus at $\mathrm{pH}=4$. ( $\mathbf{-}$ ) activity partitioning coefficient, ( $\square$ ) yield in the foamate 


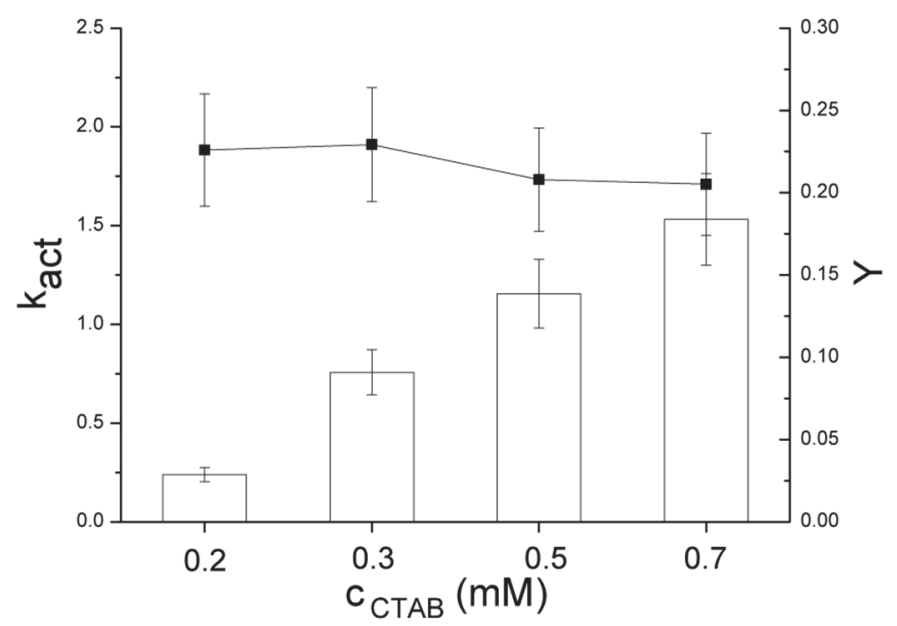

Fig. 7. Influence of CTAB concentration on enzyme partitioning and foamate yield of laccase from $P$. sapidus at $\mathrm{pH}=7$. ( $\square$ ) activity partitioning coefficient, ( $\square$ ) yield in the foamate

As a next step, another surfactant, Polysorbate 80 , was investigated. Polysorbate 80 is a non-ionic surfactant, which does not foam as effectively as cationic surfactants such as CTAB. There are reports of using it as a foaming agent for foam fractionation (Linke et al, 2005; Bezelgues et al., 2008).

For the foam fractionation of laccase experiments, two different Polysorbate 80 concentrations were investigated: $0.5 \mathrm{mM}$ and $1.0 \mathrm{mM}$. The surfactant has a very low critical micelle concentration of 0.012 $\mathrm{mM}$, therefore the experiments were performed with maximum foamability. In the case of C. unicolor culture supernatant, the foam was stable enough to reach the top of the column only with the concentration of $1.0 \mathrm{mM}$. In the case of $P$. sapidus culture supernatant, the foam stability was insufficient at all examined concentrations.

Therefore, a set of experiments was conducted for $C$. unicolor laccase at $c_{\text {Polysorbate } 8}=1.0$ at different $\mathrm{pH}$ values, the data of which was presented in Fig. 8 .

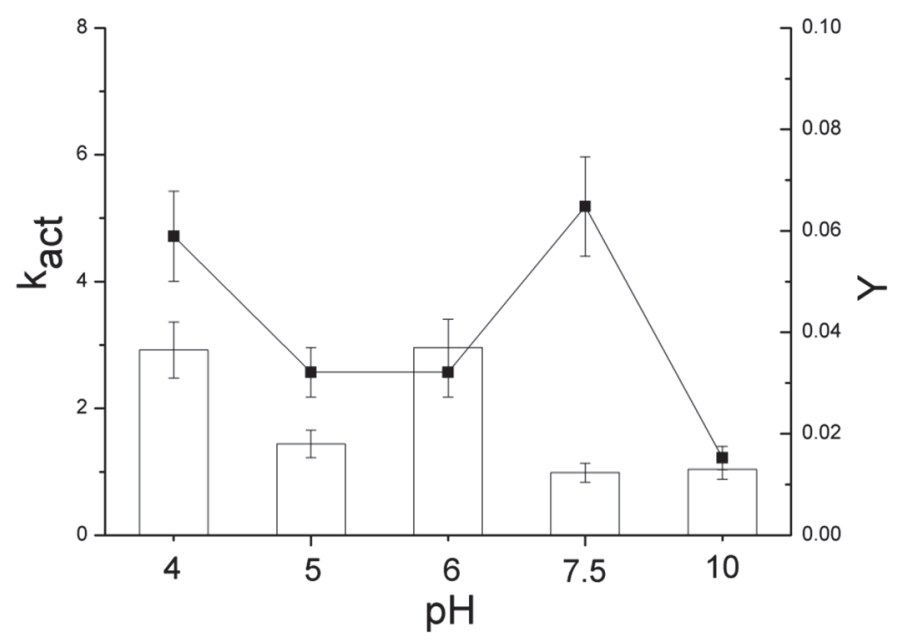

Fig. 8. Influence of $\mathrm{pH}$ on enzyme partitioning and foamate yield of laccase from C. unicolor at $c_{\text {Polysorbates } 0}=1.0 \mathrm{mM}$. (-) activity partitioning coefficient, () yield in the foamate

In comparison to the results of foam fractionation with the use of $\mathrm{CTAB}$, both the activity partitioning coefficients and the yields are significantly lower. At $\mathrm{pH}=7.5$ the $k_{\text {act }}$ did not exceed 6 , and the highest yield was lower than 0.04 . 


\section{CONCLUSIONS}

Foam fractionation of laccase from crude culture supernatants of $C$. unicolor and P. sapidus is a promising method of concentration of the enzyme, provided a proper surfactant supplement is used. Cetyltrimethylammonium bromide addition in the concentration of $0.5 \mathrm{mM}$ significantly improves the foaming of the system without draining too much water towards the foamate, which results in higher enzyme partitioning coefficients at the cost of higher yield in the foamate. Polysorbate 80 as the foaming agent is not as effective as CTAB in terms of laccase enrichment in the foam fractionation process.

Although partitioning coefficients of almost 200 were obtained, recoveries of over $50 \%$ were not possible to achieve without diluting the foamate, which means that although it is possible to satisfactorily concentrate the enzyme, the majority of it remains within the retentate. Therefore, it is advised to employ other downstream processing methods along with foam fractionation. Also, it is important to note that foam fractionation is only a method for concentration of laccase from culture supernatants, not purification. Additional steps of separating the enzyme from other proteins and the surfactant must be taken in order to obtain a pure product.

In general, the foam fractionation process is more efficient for the culture supernatant of $C$. unicolor than that of $P$. sapidus. It may be caused by higher enzyme content within the supernatant of $C$. unicolor or differences in physicochemical properties of laccases from the two investigated strains.

The results are promising for further investigation of the process in the form of continuous foam fractionation.

The research was conducted as a part of a project number UMO-2013/11/B/ST8/00337 financed by the National Science Centre. The authors would like to thank Dr. Merz for providing the foam fractionantion equipment.

\section{SYMBOLS}

$\begin{array}{ll}a c t & \text { enzymatic activity, } \mathrm{U} / 1 \\ d & \text { thickness of the sample, } \mathrm{mm} \\ D & \text { dilution coefficient } \\ E & \text { absorbance } \\ k_{\text {act }} & \text { activity partitioning coefficient } \\ t & \text { time, min } \\ V & \text { volume of the phase, } \mathrm{ml} \\ V_{s} & \text { volume of the supernatant sample, } \mu 1 \\ V_{t} & \text { total volume of the sample, } \mu 1 \\ x & \text { mass fraction, wt- } \% \\ Y & \text { yield }\end{array}$

Greek symbols

$\varepsilon \quad$ extinction coefficient at $420 \mathrm{~nm}$ wavelength, $1 /(\mathrm{mmol} \mathrm{cm})$

$\begin{array}{ll}\text { Subscripts } & \\ \text { foam } & \text { foamate } \\ \text { ret } & \text { retentate } \\ \text { ini } & \text { initial }\end{array}$




\section{REFERENCES}

Bacon J.R., Hemmant J.W., Lambert N., Moore R., Wright D.J., 1988. Characterization of the foaming properties of lysozymes and $\alpha$-lactalbumins: A structural evaluation. Food Hydrocolloid, 2, 225-245. DOI: 10.1016/s0268005x(88)80020-1.

Bezelgues J.B., Serieye S., Crosset-Perrotin L., Leser M.E., 2008. Interfacial and foaming properties of some food grade low molecular weight surfactants. Colloid Surfaces A, 331, 56-62. DOI: 10.1016/j.colsurfa.2008.07.022.

Blatkiewicz, M., Prinz, A., Górak, A., Ledakowicz, S., 2016. Partitioning of Cerrena unicolor laccase activity in an aqueous two-phase system. Chem. Process Eng., 37, 269-280. DOI: 10.1515/cpe-2016-0022.

Burghoff B., 2012. Foam fractionation applications. J. Biotech., 161, 126-137. DOI: 10.1016/j.jbiotec.2012.03.008.

Chai J., Loha V., Prokop A., Tanner R.D., 1998. Effect of bubble velocity and pH step changes on the foam fractionation of sporamin. J. Agr. Food Chem., 46, 2868-2872. DOI: 10.1021/jf970929b.

Claus H., Filip Z., 1997. The evidence of a laccase-like enzyme activity in a Bacillus sphaericus strain. Microbiol. Res., 152, 209-216. DOI: 10.1016/s0944-5013(97)80014-6.

Cohen R., Persky L., Hadar Y., 2002. Biotechnological applications and potential of wood-degrading mushrooms of the genus Pleurotus. Appl. Microbiol. Biot., 58, 582-594. DOI: 10.1007/s00253-002-0930-y.

Diamantidis G., Effosse A., Potier P., Bally R., 2000. Purification and characterization of the first bacterial laccase in the rhizospheric bacterium Azospirillum lipoferum. Soil Biol. Biochem., 32, 919-927. DOI: 10.1016/s0038-0717(99)00221-7.

Du L., Loha V., Tanner R.D., 2000. Modeling a protein foam fractionation process, In: Finkelstein M., Davison B.H. (Eds.), Twenty-First Symposium on Biotechnology for Fuels and Chemicals. Humana Press, 1087-1099. DOI: $10.1007 / 978-1-4612-1392-5 \_85$.

Gerken B.M., Nicolai A., Linke D., Zorn H., Berger R.G., Parlar H., 2006. Effective enrichment and recovery of laccase C using continuous foam fractionation. Sep. Purif. Technol., 49, 291-294. DOI: 10.1016/j.seppur.2005.09.015.

Harvey B.M., Walker J.R.K., 1999. Studies with plant laccases: I. Comparison of plant and fungal laccases. J. Biochem. Mol. Biol. Biophys., 3, 45-51.

Lemlich R., 1968. Adsorptive bubble separation methods-foam fractionation and allied techniques. Ind. Eng. Chem., 60, 16-29. DOI: 10.1021/ie50706a005.

Li R., Wu Z., Wang Y., Ding L., Wang Y., 2016. Role of pH-induced structural change in protein aggregation in foam fractionation of bovine serum albumin. Biotech. Rep., 9, 46-52. DOI: 10.1016/j.btre.2016.01.002.

Lindeberg G., Holm G., 1952. Occurrence of tyrosinase and laccase in fruit bodies and mycelia of some Hymenomycetes. Physiol. Plantarum, 5, 100-114. DOI: 10.1111/j.1399-3054.1952.tb08234.x.

Linke D., Zorn H., Gerken B., Parlar H., Berger R. G., 2007. Laccase isolation by foam fractionation-new prospects of an old process. Enzyme Microb. Tech., 40, 273-277. DOI: 10.1016/j.enzmictec.2006.04.010.

Linke D., Zorn H., Gerken B., Parlar H., Berger R.G., 2005. Foam fractionation of exo-lipases from a growing fungus (Pleurotus sapidus). Lipids, 40, 323-327. DOI: 10.1007/s11745-005-1389-x.

Majcherczyk A., Johannes C., Hüttermann A., 1998. Oxidation of polycyclic aromatic hydrocarbons (PAH) by laccase of Trametes versicolor. Enzyme Microbial. Tech., 22, 335-341. DOI: 10.1016/s0141-0229(97)00199-3.

Merz J., Burghoff B., Zorn H., Schembecker G., 2011a. Continuous foam fractionation: Performance as a function of operating variables. Sep. Purif. Technol., 82, 10-18. DOI: 10.1016/j.seppur.2011.07.023.

Merz J., Zorn H., Burghoff B., Schembecker G., 2011b. Purification of a fungal cutinase by adsorptive bubble separation: A statistical approach. Col. Surfaces A, 382, 81-87. DOI: 10.1016/j.seppur.2009.06.021.

Prinz A., Zeiner T., Vössing T., Schüttmann I., Zorn H., Górak A., 2012. Experimental investigation of laccase purification using aqueous two-phase extraction. Chem. Eng. Trans., 27, 349-354. DOI: 10.14233/ajchem.2014.17063.

Prinz, A., Koch, K., Górak, A., Zeiner, T., 2014. Multi-stage laccase extraction and separation using aqueous twophase systems: Experiment and model. Process Biochem., 49, 1020-1031. DOI: 10.1016/j.procbio.2014.03.011.

Raja S., Murty V. R., Thivaharan V., Rajasekar V., Ramesh V., 2011. Aqueous two phase systems for the recovery of biomolecules-a review. Sci. Tech., 1, 7-16. DOI: 10.5923/j.scit.20110101.02.

Reddy G.V., Babu P.R., Komaraiah P., Roy K.R.R. M., Kothari I.L., 2003. Utilization of banana waste for the production of lignolytic and cellulolytic enzymes by solid substrate fermentation using two Pleurotus species (P. ostreatus and P. sajor-caju). Process Biochem., 38, 1457-1462. DOI: 10.1016/s0032-9592(03)00025-6. 
Scherer M., Fischer R., 1998. Purification and characterization of laccase II of Aspergillus nidulans. Arch. Microb., 170, 78-84. DOI: 10.1007/s002030050617.

Shea A.P., Crofcheck C.L., Payne F.A., Xiong Y.L., 2009. Foam fractionation of $\alpha$ lactalbumin and $\beta$ lactoglobulin from a whey solution. Asia Pac. J. Chem. Eng., 4, 191-203. DOI: 10.13031/2013.21982.

Songulashvili G., Elisashvili V., Wasser S.P., Nevo E., Hadar Y., 2007. Basidiomycetes laccase and manganese peroxidase activity in submerged fermentation of food industry wastes. Enzyme Microb. Tech., 41, 57-61. DOI: 10.1016/j.enzmictec.2006.11.024.

Stowers C.C., Makarov V., Walker A., Edwards R.A., Tanner R.D., 2009. Effect of air flow rate on the foam fractionation of a mixture of egg white and egg yolk. Asia Pac. J. Chem. Eng., 4, 180-183. DOI: 10.1002/apj.227.

Uraizee F., Narsimhan G., 1990. Foam fractionation of proteins and enzymes: I. Applications. Enzyme Microb. Tech., 12, 232-233. DOI: 10.1016/0141-0229(90)90045-r.

Walker J.R., McCallion R.F., 1980. The selective inhibition of ortho-and para-diphenol oxidases. Phytochemistry, 19, 373-377. DOI: 10.1016/0031-9422(80)83184-0.

Xu F.,1996. Oxidation of phenols, anilines, and benzenethiols by fungal laccases: correlation between activity and redox potentials as well as halide inhibition. Biochem., 35, 7608-7614. DOI: 10.1021/bi952971a.

Zorn H., Breithaupt D.E., Takenberg M., Schwack W., Berger R.G., 2003. Enzymatic hydrolysis of carotenoid esters of marigold flowers (Tagetes erecta L.) and red paprika (Capsicum annuum L.) by commercial lipases and Pleurotus sapidus extracellular lipase. Enzyme Microb. Tech., 32, 623-628. DOI: 10.1016/s01410229(03)00020-6. 